\title{
High-density lipoproteins: an emerging target in the prevention of cardiovascular disease
}

\author{
Belinda A Cutri ${ }^{1}$, Neil J Hime ${ }^{2}$, Stephen J Nicholls ${ }^{3}$ \\ ${ }^{1}$ The Heart Research Institute, Camperdown, Sydney, NSW 2050, Australia; ${ }^{2}$ Department of Immunology, The Scripps Research \\ Institute, La Jolla, CA 92037, USA; ${ }^{3}$ Department of Cardiovascular Medicine, The Cleveland Clinic Foundation, Mail Code JJ65, \\ 9500 Euclid Avenue, Cleveland, OH 44195, USA
}

High-density lipoproteins (HDLs) have been well established to protect against the development of atherosclerotic cardiovascular disease. It has become apparent that in addition to the promotion of reverse cholesterol transport, HDLs possess a number of additional functional properties that may contribute to their beneficial influence on the arterial wall. A number of exciting therapeutic strategies have been developed that target HDL and its ability to protect against the development of atherosclerotic plaque. This paper will review how the promotion of the functional properties of HDL inhibits the formation of atherosclerotic plaque and stabilises lesions in patients with established disease.

Cell Research (2006) 16:799-808. doi:10.1038/sj.cr.7310097; published online 3 October 2006

Keywords: high-density lipoproteins, cardiovascular disease, atherosclerotic plaque, stabilises lesions

\section{Introduction}

The last two decades has seen a large body of evidence supporting a role for aggressive modification of established risk factors in preventing clinical events attributable to atherosclerotic coronary heart disease (CHD). As a result, a number of pharmacological agents have become integral components of cardiovascular preventive strategies. This prompted two Nobel laureates to propose that CHD would be eradicated by the early stages of this century [1]. While these agents have made a substantial impact, it has become apparent that many patients continue to experience clinical events. There is an ongoing need to identify new therapeutic targets to further reduce clinical risk. High-density lipoprotein-cholesterol (HDLC) has emerged as an attractive target in the search for new pharmacological strategies.

Correspondence: Stephen J Nicholls

Tel: +1-216-445-4062; Fax: +1-216-445-5497;

E-mail: nichols1@ccf.org

\section{What are HDLs}

HDLs represent the plasma fraction of lipoproteins in the density range $1.063-1.21 \mathrm{mg} / \mathrm{mL}$. The HDL fraction includes a wide range of circulating particles that demonstrate marked heterogeneity in terms of their shape, size, surface charge and lipid composition. The basic structure involves a lipid core surrounded by surface containing a phospholipid bilayer, free cholesterol and a number of apolipoproteins (A-I, A-II, A-IV, C, D, E and J). The heterogeneous nature of circulating HDL results from the constant remodelling of particles in response to a range of plasma factors [2].

\section{Protective properties of HDL-C: lessons from hu- man studies}

Fifty years have passed since the initial report that patients presenting with a myocardial infarction had lower levels of the lipoprotein fraction that demonstrated $\alpha$-migrating mobility on gel electrophoresis, later identified as HDL-C [3]. A number of large population studies have reported that the incidence of clinical CHD was inversely correlated with plasma levels of HDL-C [4, 5]. For every $1 \mathrm{mg} / \mathrm{dL}$ increase in plasma HDL-C, the incidence of clini- 
cal events declines by $2-3 \%$. In fact, plasma HDL-C was found to be the strongest biochemical predictor of clinical events in the Framingham Heart Study [5]. Plasma HDL-C levels were also found to be an important predictor of event rates in clinical trials testing the impact of lipid lowering therapies. In trials of both statins [6, 7] and fibrates [8], the event rate in placebo-treated patients (and therefore the relative risk reduction seen with active treatment) was greatest in those subjects with a low plasma HDL-C level at baseline.

\section{Protective properties of HDL: lessons from animal studies}

A large body of evidence has emerged from animal studies to suggest that elevation of HDL-C is protective. Badimon and colleagues were the first to report that administration of HDL-C inhibited lesion formation and promoted regression of pre-existent lesions in cholesterol-fed rabbits $[9,10]$. Since that time, a number of groups have reported that elevation of plasma HDL-C by either infusion of HDL or apolipoprotein A-I (apoA-I, the predominant protein of HDL) [11-15] or transgenic expression of human apoA-I [16-18] has a beneficial impact on lesion size in animal models of atherosclerosis. In addition to a favourable effect on the early stages of atheroma formation, elevation of HDL-C by either transgenic expression of apoA-I [18] or infusion of synthetic HDL-containing apoA-I Milano (AIM) [12], a variant of apoA-I, reduced the size, lipid and inflammatory composition of established lesions.

\section{HDL facilitates reverse cholesterol transport}

While a number of functional properties of HDL have been described (Figure 1), the best characterised is its pivotal role in the promotion of reverse cholesterol trans-

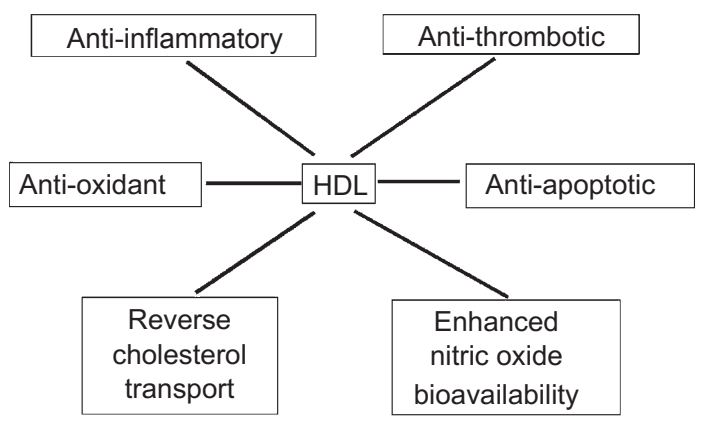

Figure 1 Potential antiatherosclerotic functional properties of HDLs. port, the process by which cholesterol is mobilised from peripheral tissue to the liver [19]. HDL is the primary acceptor of cholesterol effluxed from peripheral cells via a number of mechanisms including passive diffusion across the cellular membrane and active transport by a family of transmembrane ATP-binding protein channels [20]. The best-characterised member of this family, ABCA1, preferentially effluxes cholesterol to lipid deplete or free forms of apoA-I [21]. Patients with Tangier's disease, a syndrome characterised by low plasma levels of HDL-C and impaired cholesterol efflux, are deficient in ABCA1 [22]. It has recently been reported that other ATP-binding proteins, ABCG1 and ABCG5 [23, 24], are involved in the efflux of cholesterol to lipidated HDL particles. Immense interest has been focused on the development of pharmacologic strategies that promote the expression of these transmembrane proteins and thus facilitate reverse cholesterol transport.

Once cholesterol has been effluxed to the HDL particle, it is rapidly esterified by lecithin:cholesterol acyltransferase, and subsequently stored within the core of the HDL-C particle. As the particle surface remains relatively deplete of cholesterol, this maintains the gradient driving efflux from cells to the HDL particle. Cholesterol is subsequently transported to the liver where it is taken up by the scavenger receptor SR-BI. Alternatively, esterified cholesterol is transferred to apoB-containing lipoproteins, such as very low-density lipoproteins and low-density lipoproteins (LDL), in a process facilitated by cholesteryl ester transfer protein (CETP). Following transfer to apoB-containing lipoproteins, cholesterol is either taken up by the liver via the LDL receptor or delivered to cells in the periphery. In the liver, the cholesterol is used for either lipoprotein synthesis or is excreted in the bile salts.

\section{Functional properties of HDL beyond lipids}

\section{Antioxidant properties}

HDL attenuates the bioavailability of a number of prooxidant species that have been implicated in the propagation of atherogenesis. HDL inhibits the oxidative modification of LDL [25]. Non-modified forms of LDL are not proatherogenic [26]. The finding that HDLs possess a number of antioxidant factors, including paraoxonase and platelet-activating factor - acetylhydrolase [27], and are the major in vivo sink for lipid hydroperoxides [28], provides a number of potential mechanisms by which oxidative modification of LDL is impaired. Administration of HDL in both cellular [29] and animal [30] settings has also been reported to inhibit the generation of reactive oxygen species, such as superoxide, and restore its physiological balance to nitric oxide (NO) (Figure 2). 


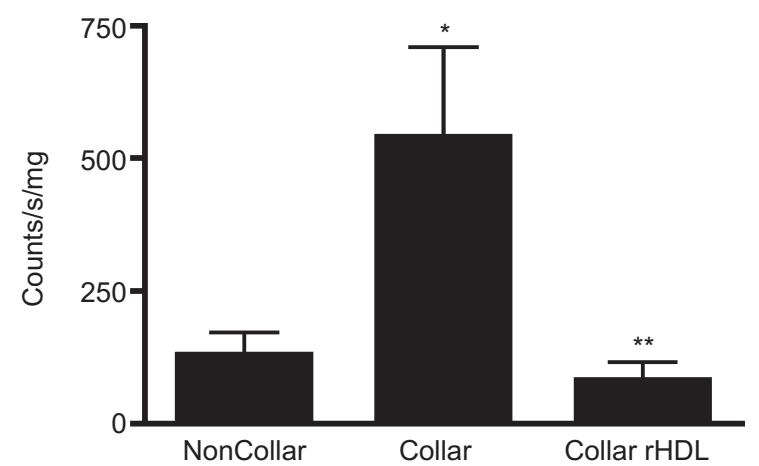

Figure 2 Expression of reactive oxygen species in the arterial wall detected by lucigenin chemiluminescence. The increased expression stimulated by application of a periarterial collar was attenuated by administration of rHDL. ${ }^{*} p<0.01$ for comparison with non-collared vessels and $* * p<0.001$ for comparison with saline-infused animals (adapted from Circulation 2005; 111:1543-1550).

\section{Anti-inflammatory properties}

HDLs modulate a number of inflammatory events that participate in the formation of atherosclerotic plaque and its evolution to clinical ischemia. HDLs inhibit the expression of proinflammatory adhesion molecules [31-33] and chemokines by endothelial cells and subsequent monocyte chemotaxis [34], key early events in atherogenesis. These in vitro properties have been reported to differ markedly between HDL isolated from different subjects $[35,36]$. The finding that altering the phospholipid composition of reconstituted HDL influenced their ability to inhibit adhesion molecule expression provides one potential mechanism for this heterogeneity [37]. These benefits have been extended to the in vivo setting, where elevation of HDL-C resulted in a reduction in the vascular expression of adhesion molecules and chemokines and infiltration of inflammatory cells into the arterial wall $[12,14,18]$. Given that these findings are derived from studies involving hypercholesterolaemic animals, it has been proposed that the anti-inflammatory properties are simply a consequence of cholesterol efflux from the arterial wall.

HDL was recently demonstrated to possess anti-inflammatory properties in a normocholesterolaemic model of acute vascular inflammation [30]. The vascular infiltration by neutrophils and endothelial expression of adhesion molecules stimulated by application of a periarterial collar was markedly attenuated by infusion of rHDL to chow-fed rabbits (Figure 3). Given that the animals had low systemic cholesterol levels, it is unlikely that there was a substantial degree of cholesterol efflux from the arterial wall, supporting a primary anti-inflammatory role of HDL in vivo.

Inflammatory factors play a major role in determining the propensity of established atherosclerotic plaque to rupture and promote thrombus formation. Elevation of HDL-C, via infusion of HDL [12] or transgenic expression of apoA-I [18], results in a reduction of macrophages and chemokines within established atherosclerotic lesions. This was further supported by the recent report that infusion of small amounts of reconstituted or native HDL, without an increase in systemic HDL-C levels, rapidly reduces lesion size (Figure 4) and increases the ratio of smooth muscle cells to macrophages (Figure 5) in a model of established atherosclerotic plaque, induced by aortic balloon denudation in the cholesterol-fed rabbit [38]. This suggests that the quality of HDL that is administered, rather than the systemic level of HDL-C achieved, is of particular importance in potential remodelling of established atherosclerotic plaque and its proclivity to result in clinical ischaemia.

\section{Other properties}

HDL has been reported to possess a number of potentially antithrombotic properties including inhibition of platelet activation and promotion of endogenous fibrinolytic and anticoagulant systems [39]. The finding that HDL increases
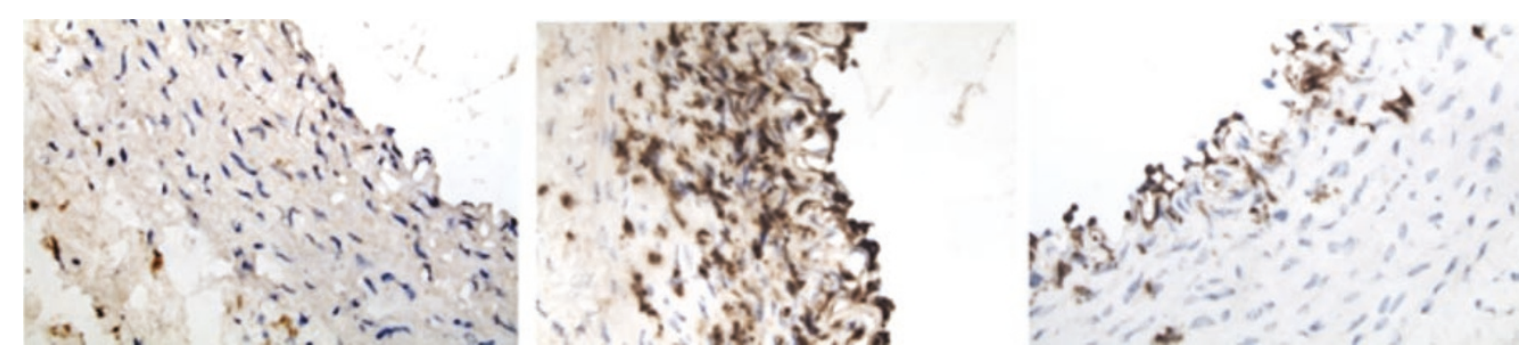

Figure 3 Infiltration of neutrophils into the vascular wall of carotid arteries without (left panel) and with application of a periarterial collar (middle panel) in animals infused with saline. The collar-induced neutrophil influx is markedly attenuated by infusion of animals with reconstituted HDL (right panel) (adapted from Circulation 2005; 111:1543-1550). 


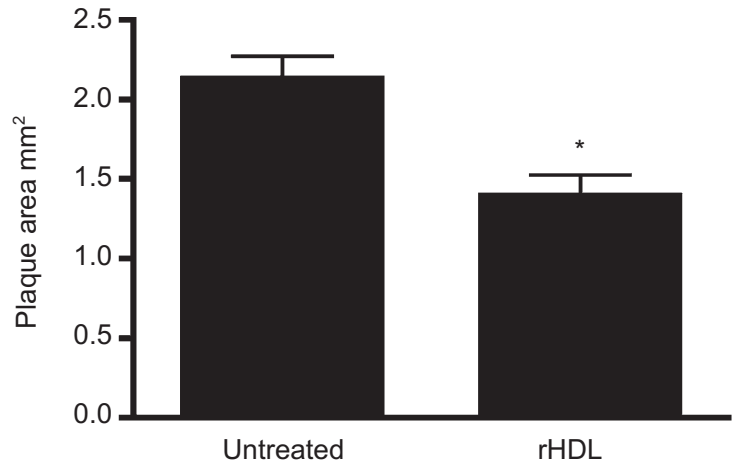

Figure 4 Atherosclerotic lesion size in the abdominal aorta in rabbits that received no treatment or infusions of reconstituted HDL. ${ }^{*} p<0.05$ for comparison with untreated animals (adapted from Arterioscler Thromb Vasc Biol 2005; 25:2416-2421).
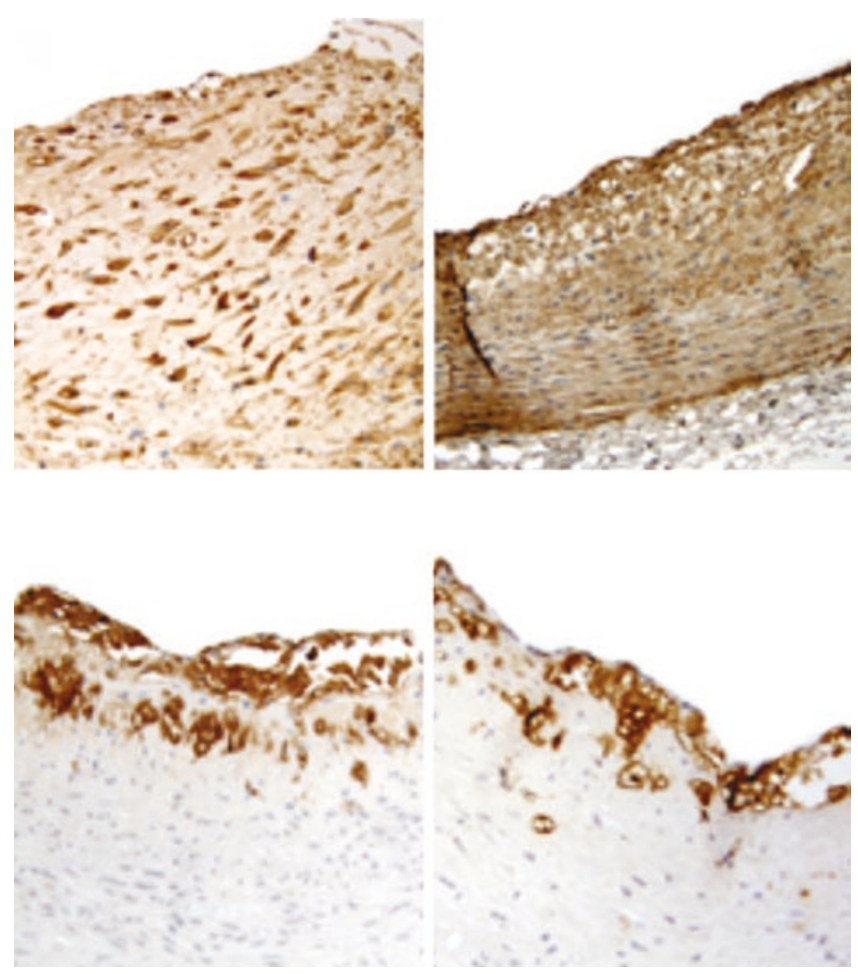

Figure 5 Representative staining of atherosclerotic lesions for smooth muscle cells (upper panels) and macrophages (lower panels) in animals that received no treatment (left panels) or infusions of reconstituted HDLs (right panels) (adapted from Arterioscler Thromb Vasc Biol 2005; 25:2416-2421).

NO synthesis [40] may also contribute to an antithrombotic environment. Enhanced NO production results from interaction of HDL with the scavenger receptor in caveolae resulting in increased NO synthase activity [41]. Reports that HDL improves reactivity of vascular rings in organ bath studies $[42,43]$ was extended to the human setting where infusion of rHDL restores endothelial function in subjects with hypercholesterolaemia [44] or low levels of HDL-C in the setting of heterozygous ABCA1 deficiency [45]. Reduced tissue injury in models of ischaemia-reperfusion $[46,47]$ and shock in the setting of both hypovolemia [48] and sepsis [49] is likely to result from the combination of antioxidant, anti-inflammatory and NO-enhancing activities of HDL. HDLs have also been reported to possess antiapoptotic activity [50-53], although the underlying mechanism for this property remains unresolved.

\section{Dysfunctional forms of HDL-C}

The finding that many subjects with plasma HDL-C levels that are considered to be normal or elevated have CHD [54] highlights an interesting paradox. Is it possible that not all HDL particles are protective? A number of groups have reported that when HDL particles contain apoA-II, its cholesterol efflux, antioxidant and anti-inflammatory properties are less than that seen with apoA-I-only-containing particles [55]. As a result, it has been reported that apoA-II may be either less atheroprotective or potentially proatherogenic $[55,56]$. Further, the ability of HDL to inhibit in vitro monocyte chemotaxis following stimulation with oxidised LDL is impaired in the setting of the acute phase response to influenza in mice [57]. It has also been reported that anti-inflammatory properties of HDL vary widely among different human subjects [35]. In fact, it was demonstrated that HDL isolated from subjects with elevated plasma HDL-C levels and CHD actually promoted, rather than inhibited, monocyte chemotaxis [36].

A potential mechanism underlying the heterogeneity in the functional properties of HDL is the degree of oxidative modification. Oxidative modification of HDL, either directly [58] or in the setting of glycation [59,60], has been reported to be associated with impaired cholesterol efflux capacity. It has been speculated that oxidation of various phospholipid species on HDL may contribute to its degree of functional activity [61]. In addition, it has been recently reported that apoA-I is a selective target for modification by myeloperoxidase (MPO)-generated oxidants in the in vivo setting [62-66]. ApoA-I isolated from serum of patients with CHD contained greater amounts of nitrotyrosine and chlorotyrosine, oxidative products of MPO, than circulating apoA-I from healthy controls. ApoA-I isolated from atherosclerotic plaque demonstrated substantially greater amounts of these oxidative products, suggesting that modification occurs preferentially within the arterial wall. Subsequent studies revealed that increasing oxidative 
modification of apoA-I is accompanied by an increasing impairment of ABCA1-dependent cholesterol efflux from macrophages $[65,66]$.

The demonstration that HDL function varies raises the possibility that it might potentially be modified in response to a range of interventions. It has recently been reported that the ability of HDL to inhibit proinflammatory adhesion molecule expression by endothelial cells is enhanced following consumption of a polyunsaturated fat-rich meal. In contrast, consumption of a saturated fat decreases this activity of HDL [67]. Further, statin therapy is associated with an enhanced ability of HDL to inhibit monocyte chemotaxis [36]. As statin therapy has been reported to attenuate MPO expression by macrophages and reduces systemic levels of the MPO product, nitrotyrosine [68, 69], it is also possible that this would result in a reduction in oxidative modification of apoA-I and subsequently enhanced cholesterol efflux activity.

\section{Existing therapeutic strategies to raise HDL}

Anumber of established interventions have been demonstrated to promote an increase in plasma HDL-C levels. Lifestyle modifications, with regard to diet, exercise and smoking cessation, result in a modest elevation in the plasma concentration and particle size of HDL-C. In fact, it was reported that substantial levels of exercise result in a $10 \%$ increase in HDL-C levels at best [70].

Several established pharmacologic agents that are primarily directed at lowering levels of atherogenic lipoproteins also raise HDL-C levels. While statins raise HDL-C by $5-10 \%$ [71], the greatest efficacy in terms of clinical event reduction was seen in those subjects with the lowest levels of HDL-C [6, 7]. Fibrates raise HDL-C by $5-15 \%[72,73]$ and have been demonstrated to reduce clinical events in studies of both primary [72] and secondary [73] prevention. Despite the ability of fibrates to lower triglyceride levels, their effect on clinical events was attributed more to their ability to elevate HDL-C [8]. Fibrates act primarily as agonists of the nuclear receptor peroxisome proliferator-activated receptor-alpha (PPAR- $\alpha$ ) [74]. In addition to regulating expression of a number of factors promoting reverse cholesterol transport, PPAR- $\alpha$ stimulation has also been reported to be anti-inflammatory [75]. Therefore, fibrates might potentially exert their atheroprotective properties via both their promotion of an antiatherogenic lipid profile and a direct protective influence on the arterial wall.

Nicotinic acid is the most potent HDL-C-raising agent (15-30\%) currently available [76, 77]. Long-term administration results in a reduction in clinical events [78], and when used in combination with statin therapy, promotes angiographic regression [79]. However, nicotinic acid is limited by a high incidence of intolerance, primarily related to flushing. The use of an extended release formulation, which appears to be free of these adverse events, was demonstrated to halt progression of carotid intimal-medial thickness, a measure of subclinical atherosclerosis, in association with HDL-C elevation [80]. Given that raising HDL-C with established therapies is typically modest, there is currently no defined target for HDL-C elevation. As a result, HDL-C elevation remains a secondary goal in the lipid management guidelines of the National Cholesterol Education Programme [81].

\section{Emerging therapeutic strategies to raise HDL}

The fact that LDL-C reduction is the primary goal of lipid management results from the unequivocal evidence of the efficacy of LDL-C reduction by statins in numerous clinical trials $[6,7,82,83]$. In contrast, the relative paucity of effective therapeutic options for HDL-C elevation has contributed to the lack of consensus on what would be an appropriate treatment goal. As a result, HDL-C elevation remains a secondary target for cardiovascular prevention. A number of novel strategies that promote the direct administration of HDL or influence its metabolic remodelling are in various stages of development.

\section{Infusion of synthetic $H D L$}

A number of reports have emerged to support the concept that directly infusing synthetic forms of HDL has a beneficial impact on the vasculature in humans. A single infusion of reconstituted HDL has been demonstrated to restore endothelial function in subjects with either hypercholesterolaemia [44] or low HDL-C levels in the setting of heterozygous ABCA1 deficiency [45]. In addition, infusion of reconstituted HDL is followed by an increase in faecal sterol excretion, a surrogate index of reverse cholesterol transport [84]. Given that these findings suggest that administration of HDL stimulates NO bioavailability and reverse cholesterol transport, it seems plausible that a therapeutic consequence might involve a favourable influence on atherosclerotic plaque. An exciting proof-of-concept study subsequently reported that administration of reconstituted particles containing the apoA-I variant, AIM, and phospholipid promoted regression of coronary atheroma in humans [85] (Figure 6). Forty-seven subjects, within 2 weeks of an acute coronary syndrome, received infusions of saline or rHDL containing either low $(15 \mathrm{mg} / \mathrm{kg})$ or high (45 $\mathrm{mg} / \mathrm{kg}$ ) dose AIM weekly for 5 weeks. Serial intravascular ultrasound analysis of a coronary arterial segment revealed a $4.2 \%$ reduction in atheroma volume in subjects who received infusions of rHDL. This extends the finding that 

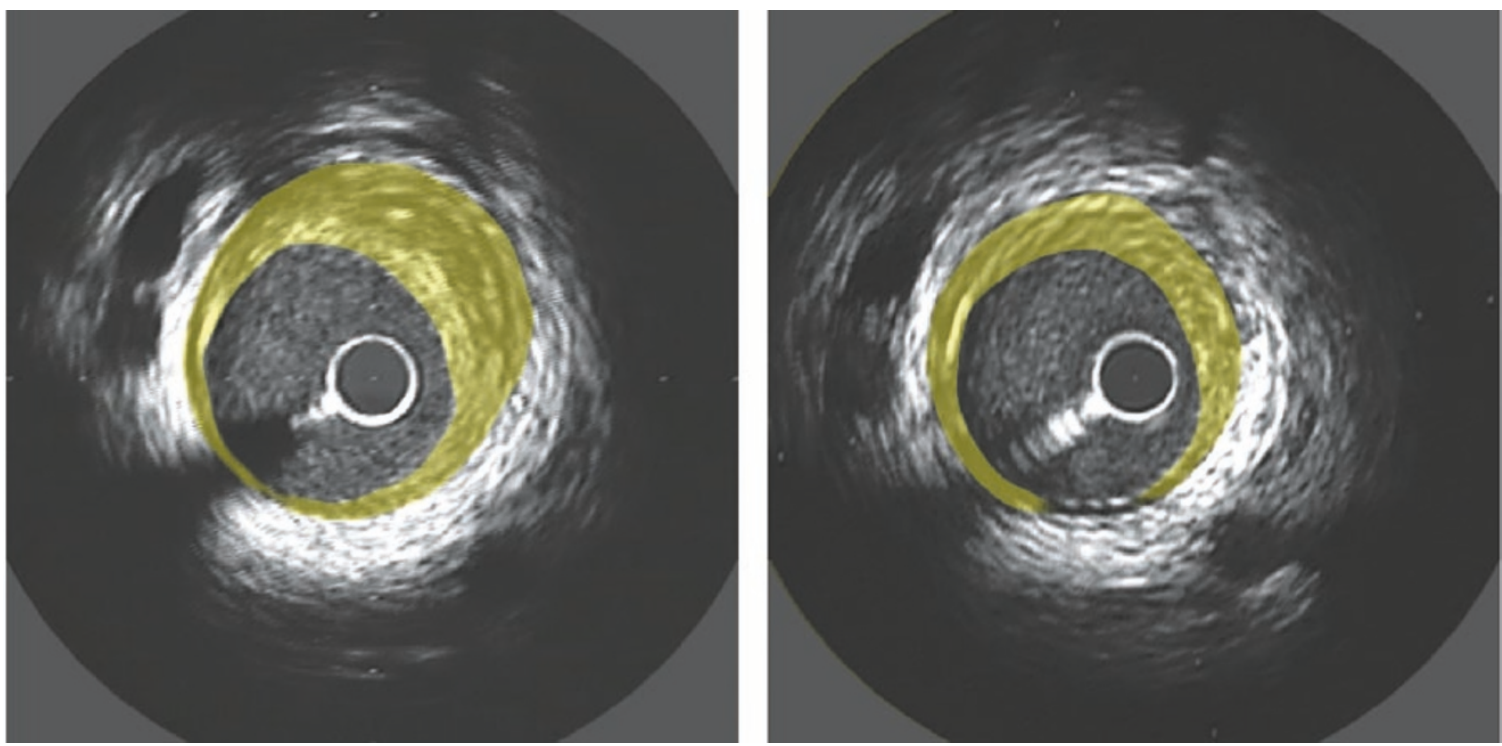

Figure 6 Representative example of regression of coronary atherosclerotic plaque (shaded areas) at a matched site imaged by intravascular ultrasound performed before (left panel) and following (right panel) treatment with reconstituted HDL particles containing AIM.

a single infusion of rHDL-containing AIM has a profound impact on atherosclerotic plaque in animal studies [12]. The potential significance of this result is further highlighted by the fact that in previous studies of antiatherosclerotic interventions, benefit was demonstrated only after a much longer time of follow-up [86, 87]. A larger trial is required to investigate this phenomenon further and to assess the potential impact on clinical events.

\section{ApoA-I mimetic peptides}

The development of short peptides, with similar structure and function to that of apoA-I, presents an alternative option to the intravenous infusion of rHDL. When synthesised with D-type amino acids, these peptides are resistant to hydrolysis by stomach acid and can therefore be administered orally [88]. One such peptide, D-4F, has been demonstrated to elevate levels of lipid-deplete HDL [88]. D-4F has been reported to enhance cholesterol efflux, enhance NO bioavailability, inhibit superoxide formation and inhibit monocyte chemotaxis in the in vitro and ex vivo setting [89]. Accordingly, D-4F has been reported to inhibit lesion formation in animal models of atherosclerosis [88-92].

\section{Phospholipid vesicles}

Phospholipid is the alternative component of nascent HDL that can be potentially administered. Phospholipid does not circulate in a free form and therefore anything that is introduced into the systemic circulation is rapidly incorporated into lipoproteins. This results in an increase in circulating forms of nascent forms of HDL containing only apoAI and phospholipid. Given that lipid-deplete forms of HDLs possess efficient cholesterol efflux and anti-inflammatory activity, it is possible that the generation of these particles would be beneficial. It has been reported that administration of phospholipid inhibits lesion formation and promotes regression of existing plaque in animal models of atherosclerosis [93]. It remains to be determined whether administration of phospholipid vesicles exerts a beneficial impact on the vasculature in humans.

\section{Enhanced PPAR agonists}

PPARs are a family of nuclear transcription factors that have been demonstrated to play pivotal roles in the regulation of a range of processes regulating metabolic homeostasis [94]. Activation of PPAR- promotes an antiatherogenic lipid milieu, characterised by increases in HDL expression and function, and lowering of plasma triglyceride. PPAR- $\gamma$ activation improves insulin sensitivity. In addition, it appears that PPAR agonists might have a direct effect at the level of the arterial wall. In particular, both PPAR- $\alpha$ and PPAR- $\gamma$ inhibit a number of critical steps in the inflammatory cascade, which may contribute to vascular protection. Established therapies including fibrates [74] and thiazolidinediones [95] have been demonstrated to act as agonists of PPAR- $\alpha$ and PPAR- $\gamma$, respectively. However, currently available agents are relatively weak agonists. A number of experimental agents that are currently in development are 
either stronger pharmacologic agonists or interact with both classes of receptors and therefore have the potential to result in a more comprehensive influence on the arterial wall.

\section{CETP inhibition}

Considerable debate has focused on whether CETP exerts an influence on atherogenesis. Once esterified cholesterol is transferred to apoB-containing lipoproteins, it can be taken up, via the LDL receptor on the liver surface. This would provide an alternative route for reverse cholesterol transport and have a potentially beneficial impact on atherogenesis. On the other hand, given that apoB-containing lipoproteins might alternatively deliver esterified cholesterol to peripheral tissues, including the arterial wall, this process might promote atheroma formation. Conflicting data have emerged from epidemiological studies. Populations with a high incidence of CETP deficiency appear to be relatively protected from CHD in some, but not all, studies [96]. The development of a number of experimental approaches to inhibit CETP activity has produced consistent results in rabbit models of atherosclerosis. Administration of antisense oligonucleotides [97], a vaccine against CETP [98], and chemical inhibitors of CETP [99] have each been demonstrated to inhibit lesion formation. Administration of oral CETP inhibitors in humans has been reported to elevate HDL-C and lower LDL-C [100]. The influence of these agents on atherosclerotic plaque progression and clinical events is currently being investigated in large-scale human clinical trials.

\section{Conclusion}

HDLs possess a number of biological activities that potentially modulate pathologic events that contribute to all stages of atheroma formation and its clinical complications. As a result of an enhanced understanding of factors that promote HDL levels and function, a number of exciting therapeutic strategies are currently in development, which have the potential to have a major impact on the prevention and treatment of atherosclerotic cardiovascular disease.

\section{Acknowledgments}

SJN is supported by a Ralph Reader Overseas Research Fellowship of the National Heart Foundation of Australia.

\section{References}

1 Brown MS, Goldstein JL. Heart attacks: gone with the century? Science 1996; 272:629.

2 Barter PJ. Hugh Sinclair Lecture: The regulation and remodelling of HDL by plasma factors. Atheroscler Suppl 2002; 3:39-47.

3 Barr DP, Russ EM, Eder HA. Protein-lipid relationships in human plasma. II. In atherosclerosis and related conditions. Am J Med 1951; 11:480-493.

4 Assmann G, Schulte H, von Eckardstein A, Huang Y. Highdensity lipoprotein cholesterol as a predictor of coronary heart disease risk. The PROCAM experience and pathophysiological implications for reverse cholesterol transport. Atherosclerosis 1996; 124(Suppl):S11-S20.

5 Gordon DJ, Probstfield JL, Garrison RJ, et al. High-density lipoprotein cholesterol and cardiovascular disease. Four prospective American studies. Circulation 1989; 79:8-15.

6 Influence of pravastatin and plasma lipids on clinical events in the West of Scotland Coronary Prevention Study (WOSCOPS). Circulation 1998; 97:1440-1445.

7 Heart Protection Study Collaborative Group. MRC/BHF Heart Protection Study of cholesterol lowering with simvastatin in 20,536 high-risk individuals: a randomised placebo-controlled trial. Lancet 2002; 360:7-22.

8 Manninen V, Tenkanen L, Koskinen P, et al. Joint effects of serum triglyceride and LDL cholesterol and HDL cholesterol concentrations on coronary heart disease risk in the Helsinki Heart Study. Implications for treatment. Circulation 1992; 85:37-45.

9 Badimon JJ, Badimon L, Fuster V. Regression of atherosclerotic lesions by high density lipoprotein plasma fraction in the cholesterol-fed rabbit. J Clin Invest 1990; 85:1234-1241.

10 Badimon JJ, Badimon L, Galvez A, Dische R, Fuster V. High density lipoprotein plasma fractions inhibit aortic fatty streaks in cholesterol-fed rabbits. Lab Invest 1989; 60:455-461.

11 Shah PK, Nilsson J, Kaul S, et al. Effects of recombinant apolipoprotein A-I(Milano) on aortic atherosclerosis in apolipoprotein E-deficient mice. Circulation 1998; 97:780-785.

12 Shah PK, Yano J, Reyes O, et al. High-dose recombinant apolipoprotein A-IMilano mobilizes tissue cholesterol and rapidly reduces plaque lipid and macrophage content in apolipoprotein E-deficient mice. Circulation 2001; 103:3047-3050.

13 Miyazaki A, Sakuma S, Morikawa W, et al. Intravenous injection of rabbit apolipoprotein A-I inhibits the progression of atherosclerosis in cholesterol-fed rabbits. Arterioscler Thromb Vasc Biol 1995; 15:1882-1888.

14 Dimayuga P, Zhu J, Oguchi S, et al. Reconstituted HDL containing human apolipoprotein A-I reduces VCAM-1 expression and neointima formation following periadventitial cuff-induced carotid injury in apoE null mice. Biochem Biophys Res Commun 1999; 264:465-468.

15 Ameli S, Hultgardh-Nilsson A, Cercek B, et al. Recombinant apolipoprotein A-I Milano reduces intimal thickening after balloon injury in hypercholesterolemic rabbits. Circulation 1994; 90:1935-1941.

16 Rubin EM, Krauss RM, Spangler EA, Verstuyft JG, Clift SM. Inhibition of early atherogenesis in transgenic mice by human apolipoprotein AI. Nature 1991; 353:265-267.

17 Plump AS, Scott CJ, Breslow JL. Human apolipoprotein A-I gene expression increases high density lipoprotein and suppresses atherosclerosis in the apolipoprotein E-deficient mouse. Proc Natl Acad Sci USA 1994; 91:9607-9611.

18 Rong JX, Li J, Reis ED, et al. Elevating high-density lipoprotein cholesterol in apolipoprotein E-deficient mice remodels advanced atherosclerotic lesions by decreasing macrophage and increasing smooth muscle cell content. Circulation 2001; 104:2447-2452. 
19 Fielding CJ, Fielding PE. Molecular physiology of reverse cholesterol transport. J Lipid Res 1995; 36:211.

20 Rothblat GH, de la Llera Moya M, Favari E, Yancey PG, Kellner-Weibel G. Cellular cholesterol flux studies: methodological considerations. Atherosclerosis 2002; 163:1-8.

21 Oram JF. HDL apolipoproteins and ABCA1: partners in the removal of excess cellular cholesterol. Arterioscler Thromb Vasc Biol 2003; 23:720-727.

22 Oram JF. Tangier disease and ABCA1. Biochim Biophys Acta 2000; 1529:321-330.

23 Nakamura K, Kennedy MA, Baldan A, Bojanic DD, Lyons K, Edwards PA. Expression and regulation of multiple murine ATPbinding cassette transporter G1 mRNAs/isoforms that stimulate cellular cholesterol efflux to high density lipoprotein. J Biol Chem 2004; 279:45980-45989.

24 Wang N, Lan D, Chen W, Matsuura F, Tall AR. ATP-binding cassette transporters G1 and G4 mediate cellular cholesterol efflux to high-density lipoproteins. Proc Natl Acad Sci USA 2004; 101:9774-9779.

25 Navab M, Hama SY, Anantharamaiah GM, et al. Normal high density lipoprotein inhibits three steps in the formation of mildly oxidized low density lipoprotein: steps 2 and 3. J Lipid Res 2000; 41:1495-1508.

26 Chisolm GM III, Hazen SL, Fox PL, Cathcart MK. The oxidation of lipoproteins by monocytes-macrophages. Biochemical and biological mechanisms. J Biol Chem 1999; 274:25959-25962.

27 Mackness MI, Durrington PN, Mackness B. How high-density lipoprotein protects against the effects of lipid peroxidation. Curr Opin Lipidol 2000; 11:383-388.

28 Bowry VW, Stanley KK, Stocker R. High density lipoprotein is the major carrier of lipid hydroperoxides in human blood plasma from fasting donors. Proc Natl Acad Sci USA 1992; 89:1031610320.

29 Ou Z, Ou J, Ackerman AW, Oldham KT, Pritchard KA Jr. L-4F, an apolipoprotein A-1 mimetic restores nitric oxide and superoxide anion balance in low-density lipoprotein-treated endothelial cells. Circulation 2003; 107:1520-1524.

30 Nicholls SJ, Dusting GJ, Cutri B, et al. Reconstituted high density lipoproteins inhibit the acute pro-oxidant and proinflammatory vascular changes induced by a periarterial collar in normocholesterolemic rabbits. Circulation 2005; 111:1543-1550

31 Baker PW, Rye K-A, Gamble JR, Vadas MA, Barter PJ. Ability of reconstituted high density lipoproteins to inhibit cytokine-induced expression of vascular cell adhesion molecule- 1 in human umbilical vein endothelial cells. J Lipid Res 1999; 40:345-353.

32 Calabresi L, Franceschini G, Sirtori CR, et al. Inhibition of VCAM-1 expression in endothelial cells by reconstituted high density lipoproteins. Biochem Biophys Res Commun 1997; 238:61-65.

33 Cockerill GW, Rye KA, Gamble JR, Vadas MA, Barter PJ. High-density lipoproteins inhibit cytokine-induced expression of endothelial cell adhesion molecules. Arterioscler Thromb Vasc Biol 1995; 15:1987-1994.

34 Navab M, Imes SS, Hama SY, et al. Monocyte transmigration induced by modification of low density lipoprotein in cocultures of human aortic wall cells is due to induction of monocyte chemotactic protein 1 synthesis and is abolished by high density lipoprotein. J Clin Invest 1991; 88:2039-2046.

35 Ashby D, Gamble J, Vadas M, et al. Lack of effect of serum amyloid A (SAA) on the ability of high-density lipoproteins to inhibit endothelial cell adhesion molecule expression. Atherosclerosis 2001; 154:113-121.

36 Ansell BJ, Navab M, Hama S, et al. Inflammatory/antiinflammatory properties of high-density lipoprotein distinguish patients from control subjects better than high-density lipoprotein cholesterol levels and are favorably affected by simvastatin treatment. Circulation 2003; 108:2751-2756.

37 Baker PW, Rye K-A, Gamble JR, Vadas MA, Barter PJ. Phospholipid composition of reconstituted high density lipoproteins influences their ability to inhibit endothelial cell adhesion molecule expression. J Lipid Res 2000; 41:1261-1267.

38 Nicholls SJ, Cutri B, Worthley SG, et al. Impact of short-term administration of high-density lipoproteins and atorvastatin on atherosclerosis in rabbits. Arterioscler Thromb Vasc Biol 2005; 25:2416-2421.

39 Rosenson RS, Lowe GD. Effects of lipids and lipoproteins on thrombosis and rheology. Atherosclerosis 1998; 140:271-280.

40 Uittenbogaard A, Shaul PW, Yuhanna IS, Blair A, Smart EJ. High density lipoprotein prevents oxidized low density lipoprotein-induced inhibition of endothelial nitric-oxide synthase localization and activation in caveolae. J Biol Chem 2000; 275:11278-11283.

41 Yuhanna IS, Zhu Y, Cox BE, et al. High-density lipoprotein binding to scavenger receptor-BI activates endothelial nitric oxide synthase. Nat Med 2001; 7:853-857.

42 Matsuda Y, Hirata K, Inoue N. High density lipoprotein reverses inhibitory effect of oxidized low density lipoprotein on endothelium-dependent arterial relaxation. Circ Res 1993; 72:11031109.

43 Ota Y, Kugiyama K, Sugiyama S, Matsumura T, Terano T, Yasue H. Complexes of apoA-1 with phosphatidylcholine suppress dysregulation of arterial tone by oxidized LDL. Am J Physiol 1997; 273:H1215-H1222.

44 Spieker LE, Sudano I, Hurlimann D, et al. High-density lipoprotein restores endothelial function in hypercholesterolemic men. Circulation 2002; 105:1399-1402.

45 Bisoendial RJ, Hovingh GK, Levels JHM, et al. Restoration of endothelial function by increasing high-density lipoprotein in subjects with isolated low high-density lipoprotein. Circulation 2003; 107:2944-2948.

46 Calabresi L, Rossoni G, Gomaraschi M, Sisto F, Berti F, Franceschini G. High-density lipoproteins protect isolated rat hearts from ischemia-reperfusion injury by reducing cardiac tumor necrosis factor-alpha content and enhancing prostaglandin release. Circ Res 2003; 92:330-337.

47 Thiemermann C, Patel NS, Kvale EO, et al. High density lipoprotein (HDL) reduces renal ischemia/reperfusion injury. J Am Soc Nephrol 2003; 14:1833-1843.

48 Cockerill GW, McDonald MC, Mota-Filipe H, Cuzzocrea S, Miller NE, Thiemermann C. High density lipoproteins reduce organ injury and organ dysfunction in a rat model of hemorrhagic shock. FASEB J 2001; 15:1941-1952.

49 McDonald MC, Dhadly P, Cockerill GW, et al. Reconstituted high-density lipoprotein attenuates organ injury and adhesion molecule expression in a rodent model of endotoxic shock. Shock 2003; 20:551-557.

50 Speidel MT, Booyse FM, Abrams A, Moore MA, Chung BH. Lipolyzed hypertriglyceridemic serum and triglyceride-rich lipo- 
protein cause lipid accumulation in and are cytotoxic to cultured human endothelial cells. High density lipoproteins inhibit this cytotoxicity. Thromb Res 1990; 58:251-264.

51 Suc I, Escargueil-Blanc I, Troly M, Salvayre R, Negre-Salvayre A. HDL and apoA prevent cell death of endothelial cells induced by oxidized LDL. Arterioscler Thromb Vasc Biol 1997; 17:21582166.

52 Sugano M, Tsuchida K, Makino N. High-density lipoproteins protect endothelial cells from tumor necrosis factor-alpha-induced apoptosis. Biochem Biophys Res Commun 2000; 272:872876.

53 Tamagaki T, Sawada S, Imamura H, et al. Effects of high-density lipoproteins on intracellular $\mathrm{pH}$ and proliferation of human vascular endothelial cells. Atherosclerosis 1996; 123:73-82.

54 Kwiterovich PO Jr. The antiatherogenic role of high-density lipoprotein cholesterol. Am J Cardiol 1998; 82:13Q-21Q.

55 Castellani LW, Navab M, Van Lenten BJ, et al. Overexpression of apolipoprotein AII in transgenic mice converts high density lipoproteins to proinflammatory particles. J Clin Invest 1997; 100:464-474.

56 Warden CH, Hedrick CC, Qiao JH, Castellani LW, Lusis AJ. Atherosclerosis in transgenic mice overexpressing apolipoprotein A-II. Science 1993; 261:469-472.

57 Van Lenten BJ, Wagner AC, Nayak D, Hama SY, Navab M, Fogelman AM. High-density lipoprotein loses its anti-inflammatory properties during acute influenza an infection. Circulation 2001; 103:2283-2288.

58 Nagano Y, Arai H, Kita T. High density lipoprotein loses its effect to stimulate efflux of cholesterol from foam cells after oxidative modification. Proc Natl Acad Sci USA 1991; 88:6457-6461.

59 Gowri MS, Van der Westhuyzen DR, Bridges SR, Anderson JW. Decreased protection by HDL from poorly controlled type 2 diabetic subjects against LDL oxidation may be due to the abnormal composition of HDL. Arterioscler Thromb Vasc Biol 1999; 19:2226-2233.

60 Syvanne M, Castro G, Dengremont C, et al. Cholesterol efflux from Fu5AH hepatoma cells induced by plasma of subjects with or without coronary artery disease and non-insulin-dependent diabetes: importance of LpA-I:A-II particles and phospholipid transfer protein. Atherosclerosis 1996; 127:245-253.

61 Barter PJ, Nicholls S, Rye KA, Anantharamaiah GM, Navab M, Fogelman AM. Antiinflammatory properties of HDL. Circ Res 2004; 95:764-772.

62 Bergt C, Pennathur S, Fu X, et al. The myeloperoxidase product hypochlorous acid oxidizes HDL in the human artery wall and impairs ABCA1-dependent cholesterol transport. Proc Natl Acad Sci USA 2004; 101:13032-13037.

63 Nicholls SJ, Zheng L, Hazen SL. Formation of dysfunctional high-density lipoprotein by myeloperoxidase. Trends Cardiovasc Med 2005; 15:212-219.

64 Pennathur S, Bergt C, Shao B, et al. Human atherosclerotic intima and blood of patients with established coronary artery disease contain high density lipoprotein damaged by reactive nitrogen species. J Biol Chem 2004; 279:42977-42983.

65 Zheng L, Nukuna B, Brennan ML, et al. Apolipoprotein A-I is a selective target for myeloperoxidase-catalyzed oxidation and functional impairment in subjects with cardiovascular disease. J Clin Invest 2004; 114:529-541.

66 Zheng L, Settle M, Brubaker G, et al. Localization of nitration and chlorination sites on apolipoprotein A-I catalyzed by myeloperoxidase in human atheroma and associated oxidative impairment in ABCA1-dependent cholesterol efflux from macrophages. J Biol Chem 2005; 280:38-47.

67 Nicholls SJ, Lundman P, Harmer J, et al. Consumption of saturated fat impairs endothelial function and the antiinflammatory properties of high-density lipoproteins and endothelial function. Circulation 2006; 48:715-720.

68 Shishehbor MH, Aviles RJ, Brennan ML, et al. Association of nitrotyrosine levels with cardiovascular disease and modulation by statin therapy. JAMA 2003; 289:1675-1680.

69 Shishehbor MH, Brennan ML, Aviles RJ, et al. Statins promote potent systemic antioxidant effects through specific inflammatory pathways. Circulation 2003; 108:426-431.

70 Kraus WE, Houmard JA, Duscha BD, et al. Effects of the amount and intensity of exercise on plasma lipoproteins. N Engl J Med 2002; 347:1483-1492.

71 Jones P, Kafonek S, Laurora I, Hunninghake D. Comparative dose efficacy study of atorvastatin versus simvastatin, pravastatin, lovastatin, and fluvastatin in patients with hypercholesterolemia (the CURVES study). Am J Cardiol 1998; 81:582-587.

72 Manninen V, Elo MO, Frick MH, et al. Lipid alterations and decline in the incidence of coronary heart disease in the Helsinki Heart Study. JAMA 1988; 260:641-651.

73 Robins SJ, Collins D, Wittes JT, et al. Relation of gemfibrozil treatment and lipid levels with major coronary events: VA-HIT: a randomized controlled trial. JAMA 2001; 285:1585-1591.

74 Staels B, Schoonjans K, Fruchart JC, Auwerx J. The effects of fibrates and thiazolidinediones on plasma triglyceride metabolism are mediated by distinct peroxisome proliferator activated receptors (PPARs). Biochimie 1997; 79:95-99.

75 Marx N, Duez H, Fruchart JC, Staels B. Peroxisome proliferator-activated receptors and atherogenesis: regulators of gene expression in vascular cells. Circ Res 2004; 94:1168-1178.

76 Tavintharan S, Kashyap ML. The benefits of niacin in atherosclerosis. Curr Atheroscler Rep 2001; 3:74-82.

77 Vega GL, Grundy SM. Lipoprotein responses to treatment with lovastatin, gemfibrozil, and nicotinic acid in normolipidemic patients with hypoalphalipoproteinemia. Arch Intern Med 1994; 154:73-82.

78 Clofibrate and niacin in coronary heart disease. JAMA 1975; 231:360-381.

79 Brown BG, Zhao XQ, Chait A, et al. Simvastatin and niacin, antioxidant vitamins, or the combination for the prevention of coronary disease. N Engl J Med 2001; 345:1583-1592.

80 Taylor AJ, Sullenberger LE, Lee HJ, Lee JK, Grace KA. Arterial Biology for the Investigation of the Treatment Effects of Reducing Cholesterol (ARBITER) 2: a double-blind, placebocontrolled study of extended-release niacin on atherosclerosis progression in secondary prevention patients treated with statins. Circulation 2004; 110:3512-3517.

81 Grundy SM. Approach to lipoprotein management in $2001 \mathrm{Na}-$ tional Cholesterol Guidelines. Am J Cardiol 2002; 90:11i-21i.

82 Randomised trial of cholesterol lowering in 4444 patients with coronary heart disease: the Scandinavian Simvastatin Survival Study (4S). Lancet 1994; 344:1383-1389.

83 Prevention of cardiovascular events and death with pravastatin in patients with coronary heart disease and a broad range of initial cholesterol levels. The Long-Term Intervention with Pravastatin 
in Ischaemic Disease (LIPID) Study Group. N Engl J Med 1998; 339:1349-1357.

84 Angelin B, Parini P, Eriksson M. Reverse cholesterol transport in man: promotion of fecal steroid excretion by infusion of reconstituted HDL. Atheroscler Suppl 2002; 3:23-30.

85 Nissen SE, Tsunoda T, Tuzcu EM, et al. Effect of recombinant ApoA-I Milano on coronary atherosclerosis in patients with acute coronary syndromes: a randomized controlled trial. JAMA 2003; 290:2292-2300.

86 Nissen SE, Tuzcu EM, Libby P, et al. Effect of antihypertensive agents on cardiovascular events in patients with coronary disease and normal blood pressure: the CAMELOT study: a randomized controlled trial. JAMA 2004; 292:2217-2225.

87 Nissen SE, Tuzcu EM, Schoenhagen P, et al. Effect of intensive compared with moderate lipid-lowering therapy on progression of coronary atherosclerosis: a randomized controlled trial. JAMA 2004; 291:1071-1080.

88 Navab M, Anantharamaiah GM, Reddy ST, et al. Oral D-4F causes formation of pre-beta high-density lipoprotein and improves high-density lipoprotein-mediated cholesterol efflux and reverse cholesterol transport from macrophages in apolipoprotein E-null mice. Circulation 2004; 109:3215-3220.

89 Navab M, Anantharamaiah GM, Reddy ST, et al. Apolipoprotein A-I mimetic peptides. Arterioscler Thromb Vasc Biol 2005; 25:1325-1331.

90 Li X, Chyu KY, Faria Neto JR, et al. Differential effects of apolipoprotein A-I-mimetic peptide on evolving and established atherosclerosis in apolipoprotein E-null mice. Circulation 2004; 110:1701-1705.

91 Navab M, Anantharamaiah GM, Hama S, et al. Oral administration of an Apo A-I mimetic Peptide synthesized from D-amino acids dramatically reduces atherosclerosis in mice independent of plasma cholesterol. Circulation 2002; 105:290-292.

92 Navab M, Anantharamaiah GM, Hama S, et al. D-4F and statins synergize to render HDL antiinflammatory in mice and monkeys and cause lesion regression in old apolipoprotein E-null mice. Arterioscler Thromb Vasc Biol 2005; 25:1426-1432.

93 Navab M, Hama S, Hough G, Fogelman AM. Oral synthetic phospholipid (DMPC) raises high-density lipoprotein cholesterol levels, improves high-density lipoprotein function, and markedly reduces atherosclerosis in apolipoprotein E-null mice. Circulation 2003; 108:1735-1739.

94 Plutzky J. Peroxisome proliferator-activated receptors in vascular biology and atherosclerosis: emerging insights for evolving paradigms. Curr Atheroscler Rep 2000; 2:327-335.

95 Marx N, Schonbeck U, Lazar MA, Libby P, Plutzky J. Peroxisome proliferator-activated receptor gamma activators inhibit gene expression and migration in human vascular smooth muscle cells. Circ Res 1998; 83:1097-1103.

96 Barter PJ, Chapman MJ, Hennekens CH, Rader DJ, Tall AR Cholesteryl ester transfer protein. A novel target for raising HDL and inhibiting atherosclerosis. Arterioscler Thromb Vasc Biol 2003; 23:160-167.

97 Sugano M, Makino N, Sawada S, et al. Effect of antisense oligonucleotides against cholesteryl ester transfer protein on the development of atherosclerosis in cholesterol-fed rabbits. J Biol Chem 1998; 273:5033-5036.

98 Rittershaus CW, Miller DP, Thomas LJ, et al. Vaccine-induced antibodies inhibit CETP activity in vivo and reduce aortic lesions in a rabbit model of atherosclerosis. Arterioscler Thromb Vasc Biol 2000; 20:2106-2112.

99 Okamoto H, Yonemori F, Wakitani K, Minowa T, Maeda K, Shinkai $\mathrm{H}$. A cholesteryl ester transfer protein inhibitor attenuates atherosclerosis in rabbits. Nature 2000; 406:203-207.

100 Brousseau ME, Schaefer EJ, Wolfe ML, et al. Effects of an inhibitor of cholesteryl ester transfer protein on HDL cholesterol. N Engl J Med 2004; 350:1505-1515. 